Çukurova Üniversitesi Mühendislik Fakültesi Dergisi, 36(3), ss. 591-599, Eylül 2021

Cukurova University Journal of the Faculty of Engineering, 36(3), pp. 591-599, September 2021

\title{
Bir Denim Konfeksiyon İşletmesinde Otomasyon Sistemlerinin, İş Sürelerindeki İyileşmeye Olan Etkisinin Değerlendirilmesi
}

\author{
Hilal BILLGíç*1 \\ ${ }^{1}$ Malatya Turgut Özal Üniversitesi, Yeşilyurt Meslek Yüksek Okulu, Tekstil, Giyim, Ayakkabı ve \\ Deri Bölümü, Malatya
}

Geliş tarihi: 03.05.2021 Kabul tarihi: 13.09.2021

\section{$\ddot{O} z$}

Bu çalışmada, bir denim konfeksiyon işletmesinde iş istasyonlarına göre, elle ve otomatik olarak yapılan işlerin zaman etüdü yapılmış ve kıyaslanmıştır. Dikim bölümünde işlem zorluğu ve işlem süresinin uzunluğu nedeni ile otomatlara ihtiyaç duyulan işlemler de etüt edilmiştir. Yapılan etütler sonucu dikimhanede kullanılan otomatlarda işlem süresi açısından en düşük iyileşme yüzdesi \%28,94 ile rivet çakma otomatında (bu işlem, ürün yıkama öncesi yapıldığından, otomat, dikimhane departmanı içindedir), en yüksek iyileşme yüzdesi ise \%88,57 ile kemer takma otomatında kaydedilmiştir. Denim konfeksiyona has kuru işlemlerde ise, 13 adet numunenin üzerlerindeki işlemlerin hem manuel, hem de otomatik makinelerdeki işlem süreleri etüt edilmiştir. Elde edilen verilere göre zaman açısından iyileşme yüzdeleri hesaplanmıştır. Numunelere uygulanan kuru bitim işlemlerinde ise zorluk derecesine göre işlem sürelerinde \%25,52 ila \%56,25 arasında iyileşme görülmüştür.

Anahtar Kelimeler: Denim konfeksiyon, Otomasyon, Dikim otomatları, Lazer ile kuru işlemler

\section{Evaluation of the Effect of Automation Systems on Improvement in Work Period in a Denim Apparel Plant}

\begin{abstract}
In this study, the time study of manual and automatic work done by workstations in a denim garment business was compared. In the sewing department, the processes that require automatic machines due to the difficulty of processing and the length of the processing time were also studied. As a consequence of the studies performed, the lowest improvement percentage in terms of processing time was recorded in rivet fastening automat with $28.94 \%$ (this process was done before washing the product, so it was in the sewing department), the highest improvement percentage was recorded in the belt fastening automat with $88.57 \%$. In dry processes specific to denim apparel, the processing times of the processes on 13 samples were investigated both in manual and automatic machines. Based on the data obtained, the improvement percentages in terms of time were calculated. In the dry finishing processes applied to the samples, an improvement between $25.52 \%$ and $56.25 \%$ was observed in the processing times depending on the difficulty.
\end{abstract}

Keywords: Denim manufacturing, Automation, Sewing automat, Dry laser processes

*Sorumlu yazar (Corresponding author): Hilal BİLGíç, hilal.bilgic@ozal.edu.tr 
Bir Denim Konfeksiyon İşletmesinde Otomasyon Sistemlerinin, İş Sürelerindeki İyileşmeye Olan Etkisinin Değerlendirilmesi

\section{GİRIŞ}

Teknolojinin baş döndürücü bir hızla ilerlediği günümüzde, insanlardaki hız ve zaman algısı da farklı bir boyuta gelmiştir. Haberleşme, ulaşım, tedarik, üretim gibi birçok alanda teknolojinin imkânlarının kullanılması, dev sanayi kuruluşlarından en sade bireye kadar her kesimde işlemlerin hılı yapılması beklentisini oluşturmuştur. $\mathrm{Bu}$ bağlamda, imalattan depolamaya, nakliyeden dağıtıma birçok alanda ileri bilgisayar teknolojilerinin kullanılması kaçınılmaz hale gelmiştir [1].

Artan dünya nüfusuyla birlikte insanların talepleri de gün geçtikçe çoğalmıştır. Bu nedenle daha çok ürünü, mümkün olduğunca kısa sürede üretme, ürünlerin uygun şartlarda nakliyesi ve depolanması ve akabinde talep eden kesime arz edilmesi için teknolojinin imkânlarından yararlanılması gereği duyulmuştur. Ancak tüm bu işlemlerin sadece hızlı yapılması yeterli olmamakta, aynı zamanda hatasız bir şekilde yürütülmesi gerekmektedir. Yapısı gereği insan hataya açık bir varlık olduğu için, hızlı çalışması gereken sistemlerin minimum hata ile ve seri bir şekilde ilerlemesine yönelik makineleşme çalışmaları artmıştır. Sürdürülen araştırmalar ve ilerleyen teknoloji sayesinde günümüzde birçok sistemin yürütülmesi ve kontrol edilmesi otomasyon sistemleri tarafından yapılır hale gelmiştir [1]. Bu bağlamda, karşımıza çıkan ve bir işin insan ile makine arasında paylaşılması olarak tanımlanan terime otomasyon denilmektedir. Endüstriyel otomasyon ise, üretim işlemlerinin hiç insan müdahalesi olmadan ya da çok az müdahale ile sürdürülmesi olarak tanımlanabilir [2]. Otomasyonun düzeyi bir sistemde işin paylaşım yüzdesi ile belirlenir. Sistemde insan gücü yoğun ise "yarı otomasyon"; makine gücü yoğun ise "tam otomasyon" olarak adlandırılır.

Tekstil sektöründe de otomasyonla ilgili bazı akademik çalışmalara değinecek olursak;

Erol ve diğerleri, farklı bölgelerde hizmet vererek aynı ürün üreten ve benzer üretim kapasitesine sahip farklı işletmelerden alınan verilerle karşılaştırmalı bir analiz yapmış, maliyeti etkileyen unsurlar ve bu unsurların etki oranları tespit etmişlerdir. Maliyet kalemleri içerisinde malzeme ve aksesuar maliyetlerinden sonra ikinci sırada yer alan dikim bölümü işçilik maliyetlerine etki eden faktörler incelemişler, bu faktörlerle ürün birim maliyeti arasındaki bağlantıların ortaya çıkarılmasına çalışmışlardır [3]. Bu verilerde dikimhane bölümündeki otomasyon ihtiyacını açıkça ortaya koymaktadır.

Bilgiç, 2017 yılında denim konfeksiyonda otomasyon üzerine yapmış olduğu çalışmada kuru işlem uygulanmış beş numune üzerinde iyileşme oranlarının \%50'ye yakın olduğunu tespit etmiştir [4].

Yazgan Bulgun ve diğerleri hazır giyim sektöründe üretim maliyetlerini hesaplamak için web tabanlı otomasyon yazılımı geliştirmişlerdir [5].

Chin ve arkadaşları makalelerinde, Hong Kong'da otomasyon sistemlerinin benimsenmesine ve otomasyon stratejisi seçimlerinin belirlenmesine ilişkin deneysel bir çalışmanın bulgularını incelemişlerdir. Nispeten küçük örneğe rağmen, kanıtlar birçok giyim üreticisinin geleneksel operasyonlardan otomasyon sistemlerinin, araçlarının ve hizmet unsurlarının (örneğin tasarım, planlama, üretim ve pazarlama) kullanımını içeren modern operasyonlara geçtiğini ortaya koymuşlardır [6].

Li ve arkadaşları Çin'in Pearl River Delta bölgesinde yaptıkları araştırmada; tekstil sektöründe otomasyonla ortaya çıkan işgücü değişikliklerini ortaya koymuşlardır. Genel olarak, emek yoğun endüstrilerdeki otomasyonun, işçilik maliyetlerini düşürdüğünü ve şirketlerin üretim süreçlerini iyileştirmelerine yardımcı olduğunu, niteliksiz işçi sayısının azalırken nitelikli işçi sayısının arttığını vurgulamışlardır [7].

Huang ve arkadaşları çalışmalarında $\mathrm{Gu}$ ve 
diğerlerinin çalışmasının tam aksi yönde bir sistem geliştirip üç boyutlu giysi formları bloklar haline getirip iki boyutlu kalıplar elde etmişlerdir. Otomasyonun ürün geliștirme sürecini önemli ölçüde hızlandırdığına ve moda ürünlerinin pazara sunulma süresini kısaldığına vurgu yapmışlardır [8].

Cömert ve arkadaşları, Adana'da seçilmiş bir konfeksiyon işletmesinde farklı desenli iki çift pantolonun dikim prosesini incelemişler ve söz konusu ürünlerin proses analizini yapmışlardır. Giysilerin dikim hattı için zaman ölçümü ve proses analizi yapılmıştır. Çalışmada Pitch time hesaplanmış, Pitch şeması oluşturulmuş, proses analizinde dar boğazlar tespit edilmiş ve ilgili çözüm önerileri sunulmuştur [9].

Kumaş ve arkadaşları, seçilmiş bir konfeksiyon işletmesinde İş Etüdü çalışması yapmıştır. Çalışma kapsamında bir pantolon üretim süreci incelenmiştir. Çalışmada amaç; konfeksiyon işletmelerinde seçilmiş bir ürün için üretimdeki tüm işlerin dizgisel olarak kaydedilmesi ve verimsiz sürelerin ortadan kaldırılmasının araştırılmasıdır. İş etüdü metodu seçilen pantolon üretim süreci için konfeksiyon işletmesinin tüm proseslerine uygulanmıştır.

İşletmede kullanılan makinelerde veya işletme genel tesis yerleştirmede herhangi bir değişiklik yapılmamıştır. Etüt işlemi proseslerde uygulanan işlemler üzerinde gerçekleştirilmiş olup işlem sıraları değiştirilmiş veya işlemler birleştirilmiştir. Çalışmada iş etüdü çalışmalarında kullanılan iş akış şemaları ile iki el süreç şemaları kullanılarak iyileştirilmesi gereken işlemler belirlenmiş ve önerilen sistem oluşturulmuştur. Her bir birimin mevcut sistemi incelenerek dikim bölümünde iyileştirilme yapılmasına karar verilmiştir [10].

Ünal ve arkadaşları çalışmalarında klasik dikiş makineleri ile dikiş otomatları üretim yöntemlerini ekonomiklikleri açısından karşılaştırılarak en uygun üretim yöntemi önerileri ortaya koymuşlardır. Çalışmalarında kemer takma, etiket dikme, fleto cep takma, cep kapağı dikme, pantolona arka cep takma ve kemere köprü dikme otomatları kullanmışlardır.

Otomatların çoğunluğu işletmeyi birinci yılında kara geçirirken, sadece bir tanesi (cep kapağ dikme otomatı); makine değerinin çok yüksek olması nedeniyle ancak beşinci yılın sonunda kârlı olabilmiştir [11].

Çalışma Malatya'da, kümeleşmenin yaşanmaya başlandığı denim ürün üretiminde öncü, Baykanlar Denim'de yapılmıştır. İşletme bölgemizde otomasyon sistemlerini en iyi uygulayan denim konfeksiyon işletmesidir. $\mathrm{Bu}$ çalışmanın asıl amacı da denim konfeksiyonun dar boğazlarını tanımlamak, işletmede bu dar boğazlar hangi otomasyon sistemleri ile aşılmış ve iyileşme oranları ne orandadır, bunların tespitini yapmak ve eskiden tamamen el işçiliğine dayanan kuru işlemlerin otomasyon sonucu geldiği aşamayı ortaya koymaktır. Bu çalışmada özellikle bu işlemlere iş zaman etüdü yapıllmıştır.

\section{MATERYAL VE METOT}

\subsection{Materyal}

Bu çalışmada 12 adet farklı 5 cep denim pantolon ve 1 adet ceketten oluşan bir grup giysi için, denim konfeksiyondaki iş istasyonlarına göre seçilmiş işlerin manuel ve otomasyon ile zaman etüdü uygulamaları incelenmiştir.

Modelhane ve kesimhane bölümünde kullanılan otomasyon sistemleri için manuel ve otomatik serim ve kesim yapılan operasyonlar, seçilmiş 5 cep denim pantolon için kıyaslanmıştır.

Dikimhanede ise günlük üretim akışını bozmadan işletmede aynı işlemleri yapan otomatlara ve mekanik-manuel işlemlere iş zaman etüdü yapılmıştır. $\mathrm{Bu}$ işlemler; arka cep takma, köprü takma, kemer takma, etiket takma, cep ağzı kıvırma ve rivet çakmadır. Diğer dikim aşamalarında otomat kullanılmadığı için kıyaslama yapılamamıştır. 
Bir Denim Konfeksiyon İşletmesinde Otomasyon Sistemlerinin, İ̧s Sürelerindeki İyileşmeye Olan Etkisinin Değerlendirilmesi

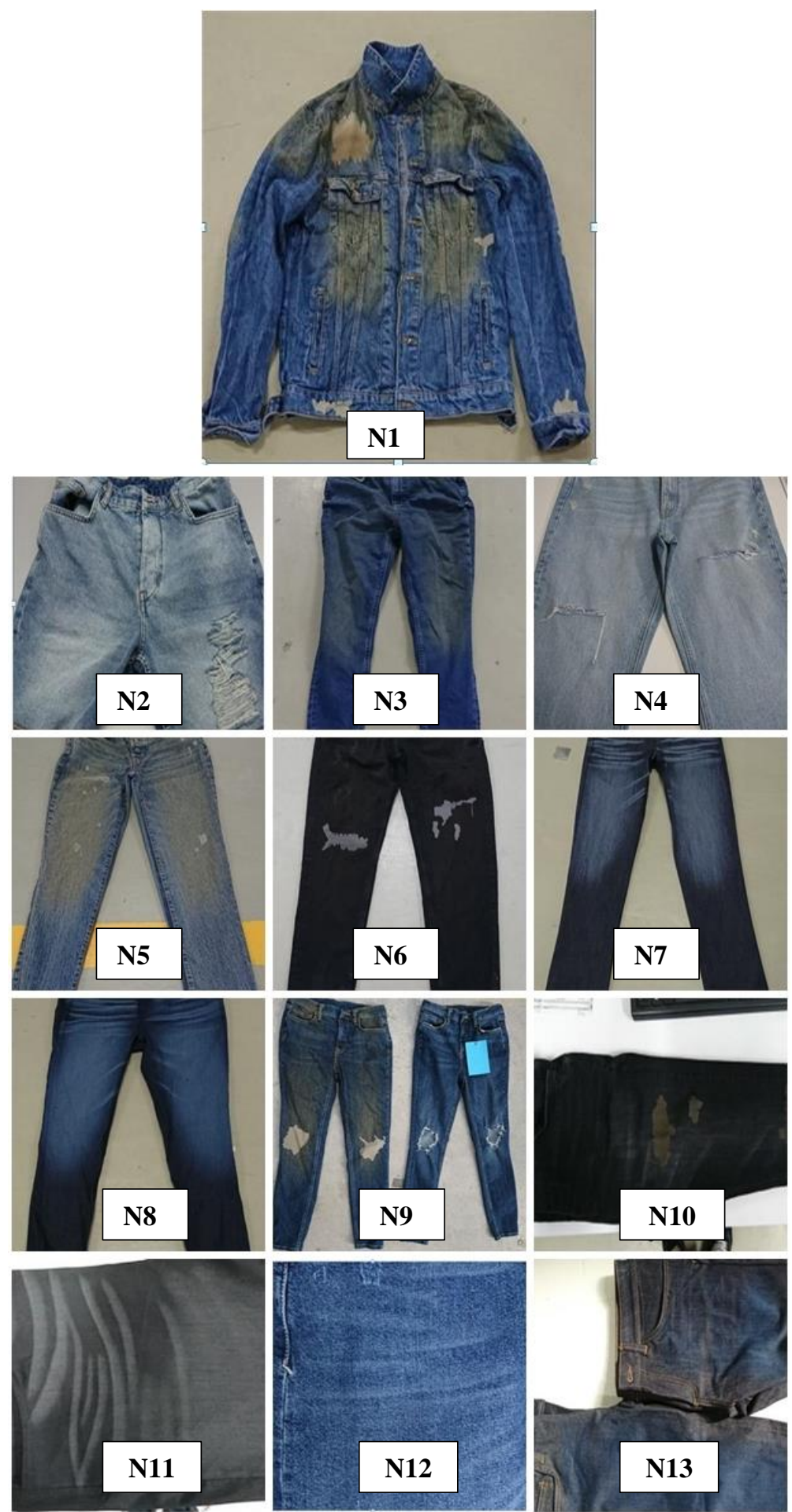

Şekil 1. Çalışmada kullanılan numuneler 
Denim konfeksiyona has kuru işlemlerde ise denim ürünlerden 13 adet numune seçilmiş, üzerlerindeki kuru işlemlerin hem manuel, hem de otomatik makinelerdeki işlem süreleri etüt edilmiştir. Her işlem 10'ar kere tekrarlanmış ve 10 ölçümün ortalaması alınmıştır. Elde edilen verilere göre iyileşme yüzdeleri hesaplanmıştır.

Çalışmada dikim bölümümdeki otomatlardan ve düz makinelerden alınan işlem süreleri denim konfeksiyon işletmesinde rutin yapılan iş-zaman ölçümlerinden alınan değerlerdir.

Denim bitim işlemleri zaman etütleri için ise 12 adet beş cep denim pantolon ve 1 adet denim mont numune olarak kullanılmıştır. Toplam 13 numunenin üzerinde farklı kuru işlemler vardır. Numunelerin üzerindeki kuru işlemlerin görülebileceği görüntüler Şekil 1'de verilmiştir.

\subsection{Metot}

Kesimhane departmanında numune ve az sayıdaki deneme üretimleri için manuel ve yarı otomatik serim ve kesim işlemleri yapılmaktadır. Üretim için ise otomatik kesim sistemi (Şekil 2) kullanılmaktadır.

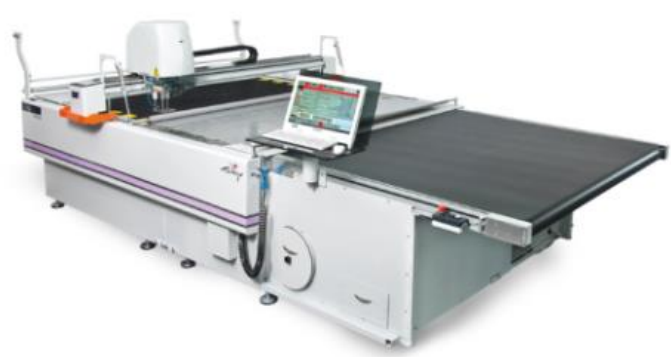

Şekil 2. Otomatik kesim sistemi [12]

Lazer teknolojisi de otomatik kesim sistemlerinden biridir. Çalışma yapılan işletmede lazer kesim teknolojisi de kullanılmıştır.

Lazer teknolojisi ile hassas ve temiz kesimler elde edilebilir. Kumaş, Şekil 3'te gösterildiği gibi malzemeler üzerinde yıpranmış kenarlar veya kıvrımlar olmaksızın bir seferde bir veya birkaç katmanı hem karmaşık hem de hassas bir şekilde kesilebilir [13].

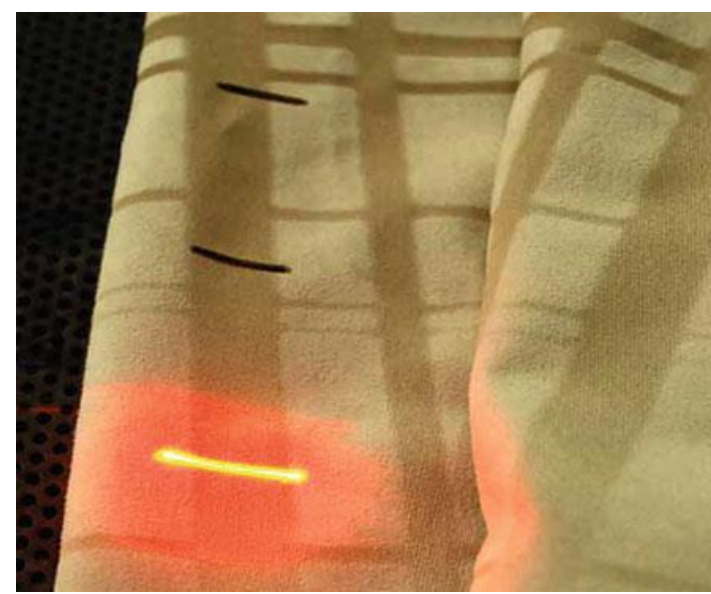

Şekil 3. Lazer kesim teknolojisi ile açılmış ilik [13]

Dikim bölümü, en fazla emek yoğun bölüm olarak manuel işlemlerin zaman etüdü için de en uygun bölümdür. Dikimhane ve denim bitim işleri departmanlarında aynı işlemler hem düz makinelerde hem de otomatik makinelerde yaptırılarak zaman etüdü analizi yapılmıştır.

Çalışmada kıyaslama yapılan iyileşme oranları aşağıdaki formül ile hesaplanmıştır;

İyileşme oranı=(Manuel işlem süresi-Otomatlarda işlem süresi)*100/ Manuel işlem süresi

Hesaplamada kullanılan etüt değerleri, 10 etüt değerinin ortalaması alınarak ve \%85 verimlilik dikkate alınarak bulunmuştur. Ölçümlerde dijital kronometre kullanılmıştır. Zaman etütü yapılan işlemler aşağıda verilmiştir:

\section{Arka cep takma}

Köprü takma

$>$ Kemer takma

$>$ Etiket takma

$>$ Cep ağzı kıvırma

Rivet çakma

Çalışmada etüt edilen kuru işlemler ise aşağıda açıklanmıştır. Kullanılan makineler Şekil 4 ve 5'de verilmiştir.

Bıyık ve Zımpara; Bıyık işlemi çizgisel, zımpara ise bölgeseldir. Seçilen modele göre, manuel 
Bir Denim Konfeksiyon İşletmesinde Otomasyon Sistemlerinin, İş Sürelerindeki İyileşmeye Olan Etkisinin Değerlendirilmesi

olarak zımpara ile aşındırma yapılır. Otomasyonda ise rengi açılacak yerler lazer makinlerinin beynine bilgisayar sistemleri ile işlenerek, o kısımlar yakılır.

Yıpratma; Denim ürünlerde uygulandığı bölgeyi kullanımdan dolayı yıpranmış görünümü vermeyi sağlayan işlemdir. Otomasyonda yıpratma, bıyık ve zımparada olduğu gibi yıpratılacak yerler lazer makinelerinin beynine bilgisayar sistemleri ile işlenerek, o kısımlar yakılır. Yıpratmanın derecesine göre lazerin yakıcılığı ve işlem süresi ayarlanabilir.

Mamül haldeki denim ürüne bıyık işlemi genelde yıkama işleminden önce ve dik lazer makinelerinde yapılır. Yıpratma işlemi ise yıkama işleminden sonra ve tablalı yatay lazer makinelerinde yapılır.

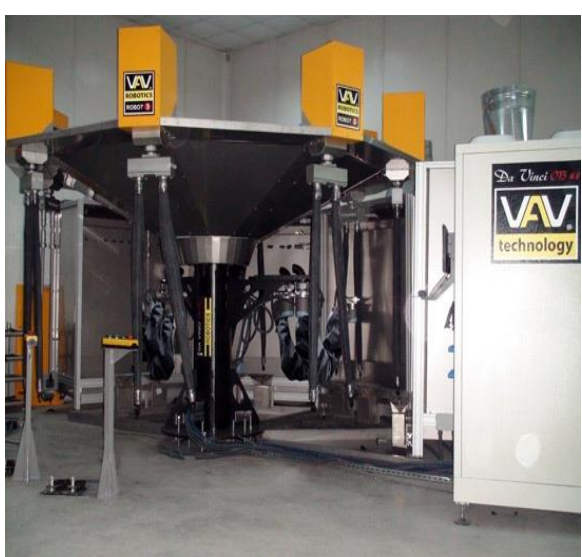

Şekil 4. Sprey robotu [14]

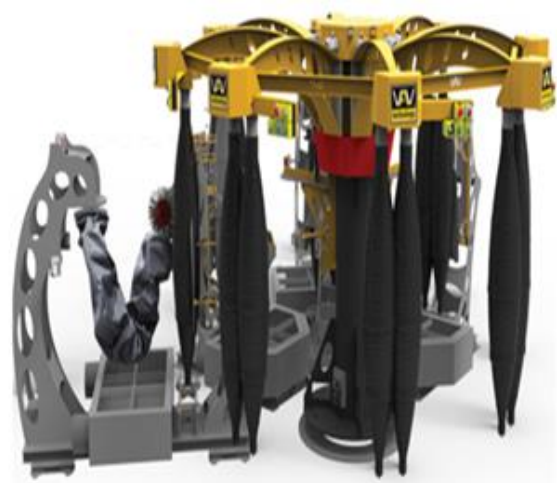

Şekil 5. Zımpara robotu [14]

\section{BULGULAR}

Farklı modellerde denim ürünlerden çalışma yapılan konfeksiyon işletmesinde serim ve kesim işlemlerinin manuel ve otomatik işlemlerinin zaman etüdü yapılmış ve birbirleriyle kıyaslanmıştır. Aynı işletmede kalıp hazırlama işlemi CAD sistemleri ile yapıldığından kalıp hazırlama için elle hazırlanmış pastal planı hazırlama süreleri kıyaslanamamıştır. Fakat daha önce yapılmış çalışmalardan CAD sistemlerinin zaman açısından çok büyük bir avantaj sağladığı bilinmektedir [15].

Kesimhanede ise hem manuel hem de otomatik kesim sistemi ile kesim yapılmaktadır. Çalışmada kullanabilmek için; kesimhanede 120 parçalık 8 metre pastal planı her iki şekilde de 35 kat serilmiş ve kesimi yapılmıştır. Veriler Çizelge 1'de verilmiştir.

Otomatik serim ve kesim sistemlerinde serim uzunluğu, kalıp parça sayısı ve kat sayısı bölümde çalışan sayısını değiştirmemekte, işletme bu otomat için 8 saatlik vardiyada 2 kişi çalıştırmaktadır. Oysa manuel serim ve kesimde serim uzunluğu, kalıp parça sayısı ve kat sayısının artması çalışanları zorlamakta, işlem süresini uzatmakta, bazen eleman takviyesi gerekmektedir.

Çizelge 1'de manuel serim ve kesim operasyonları ile otomasyon sistemlerinin kullanılması arasında işçilik, süre ve maliyet açısından çok büyük iyileşmeler olduğu açıkça görülmektedir. Manuel serim ve kesim işleminin maliyeti, otomatik serim ve kesim maliyetinin tam 30 katı çıkmıştır. Otomatik serim makineleri pahalı makineler olsa da konfeksiyon sektöründe rekabet edebilirliliği arttırdığgndan, özellikle ihracat yapan işletmelerin teslimat sürelerini kısaltabilmek için yatırım yaptığı sistemlerdir. Bu kıyaslamada bize otomatın kendini kısa sürede amorti edeceğini göstermektedir. 
Çizelge 1. Kesimhanede manuel ve otomasyonla yapılan operasyonların kıyaslanması

\begin{tabular}{|l|c|c|}
\hline & Manuel serim-Kesim & Otomatik serim-Kesim \\
\hline Serim için çalışan sayısı & 2 kişi $(3$ saat $)$ & 1 kişi $(30 \mathrm{dk})$ \\
\hline Kesim için çalışan sayısı & 6 kişi $(4$ saat $)$ & 1 kişi $(30 \mathrm{dk})$ \\
\hline Serim+Kesimiçin harcanan süre & $3+4=7$ saat & $0,5+0,5=1$ saat \\
\hline $\mathbf{1}$ çalışanın 1 saatlik maliyeti $*$ & $21 \mathrm{TL}$ & $21 \mathrm{TL}$ \\
\hline Örnek işin maliyet hesabı & $(2 * 3+6 * 4) * 21 \mathrm{TL}$ & $(1 * 0,5+1 * 0,5) * 21 \mathrm{TL}$ \\
\hline Toplam maliyet & $630 \mathrm{TL}$ & $21 \mathrm{TL}$ \\
\hline
\end{tabular}

* İşçilik maliyeti 2019 giderlerine göre yaklaşık olarak sadece kıyaslama yapabilmek için verilmiştir.

Çizelge 2'de ise dikimhanede hem manuel hem de otomatlarda yapılan bazı operasyonların süreleri verilmiş ve iyileşme oranları hesaplanmıştır. Özellikle kemer takma operasyonunda \%90'a varan iyileşmeler gerçekleşmektedir. En az iyileşme yüzdesi ise \%40,47 ile etiket takma ve \%28,94 ile rivet çakma operasyonlarında görülmüştür. Her ikisi de aksesuar takma işlemidir. Dikilen etiketlerin ve rivetlerin küçük aksesuarlar olması otomatlar da bile işlemi zorlaştırmaktadır. Dikiş otomatları sayesinde üretim süreleri kısalarak işçilik maliyeti aşağı çekilmiş olur, kalitede standartlaşma sağlanır, emeğe bağımlılık azalır ve özellikle zor ve tehlikeli işleri otomatlar yaptığından iş kazalarında azalmalar meydana gelir.

Çizelge 2. Dikimhanede kullanılan otomatlara ait zaman açısından iyileşme oranları

\begin{tabular}{|l|c|c|c|c|c|}
\hline Operasyon & $\begin{array}{c}\text { Otomatlarda } \\
\text { işlem } \\
\text { süresi (dk) }\end{array}$ & $\begin{array}{c}\text { Manuel } \\
\text { işlem } \\
\text { süresi (dk) }\end{array}$ & $\begin{array}{c}\text { Otomasyon } \\
\text { hedef (adet) }\end{array}$ & $\begin{array}{c}\text { Manuel } \\
\text { hedef (adet) }\end{array}$ & $\begin{array}{c}\text { İyileşme } \\
\text { oranı (\%) }\end{array}$ \\
\hline Arka cep takma & 0,45 & 1,95 & 1020 & 235 & 76,92 \\
\hline Köprü takma & 0,26 & 1,45 & 1795 & 317 & 82,07 \\
\hline Kemer takma & 0,32 & 2,80 & 1434 & 164 & 88,57 \\
\hline Etiket takma & 0,25 & 0,42 & 1836 & 1093 & 40,47 \\
\hline Cep ağzı kıvırma & 0,09 & 0,21 & 5100 & 2186 & 57,14 \\
\hline Rivet çakma & 0,27 & 0,38 & 1700 & 1208 & 28,94 \\
\hline
\end{tabular}

*Hesaplamalar \%85 Verim ve $540 \mathrm{dk}$ (tek vardiya) çalışma süresi baz alınarak yapılmıştır.

Çizelge 3'e göre işletmelerin otomasyon sayesinde iş gücü oranının bazı operasyonlarda $\% 50$ iyileşmenin üzerine çıktığını söyleyebiliriz. Yani bazı operasyonlarda işlem süreleri neredeyse yarıya düşmüştür. İyileşme yüzdesinin en yüksek olduğu operasyonların yıpratma olduğu görülmektedir. Bunun nedeni ise manuel olarak bu işlemin çok zor ve uzun sürmesidir. Özellikle yüksek onzlu denim kumaşlarda yıpratma yapıp kumaşta yırtık oluşturmak çok zordur. Oysa bıyık ve zımpara işlemleri yüzeysel işlemlerdir. Manuel olarak kıyaslandığında yıpratmaya göre daha kolay operasyonlardır. Ortalama iyileşme yüzdesi ise $\% 40$ civarındadır. Verim iyileşmesinin yanı sıra otomasyon kullanımı ile kalite konusunda da iyileşmeler görülmüştür. 
Bir Denim Konfeksiyon İşletmesinde Otomasyon Sistemlerinin, İş Sürelerindeki İyileşmeye Olan Etkisinin Değerlendirilmesi

Çizelge 3. İşletmede kuru işlemler bölümünde otomasyon ve manuel işlem sürelerinin kıyaslanması

\begin{tabular}{|l|c|c|c|c|c|c|}
\hline & $\begin{array}{c}\text { Manuel } \\
\text { yıpratma } \\
\text { birim } \\
\text { zamanı (dk) }\end{array}$ & $\begin{array}{c}\text { Otomasyon } \\
\text { yıpratma } \\
\text { birim } \\
\text { zamanı } \\
\text { (dk) }\end{array}$ & $\begin{array}{c}\text { Iyileşme } \\
\text { oranı } \\
\mathbf{( \% )}\end{array}$ & $\begin{array}{c}\text { Manuel } \\
\text { bıyı ve } \\
\text { zimpara } \\
\text { birim } \\
\text { zamanı (dk) }\end{array}$ & $\begin{array}{c}\text { Otomasyon } \\
\text { bıyık ve } \\
\text { zımpara } \\
\text { birim } \\
\text { zamanı (dk) }\end{array}$ & $\begin{array}{c}\text { Iyileşme } \\
\text { oranı } \\
\text { (\%) }\end{array}$ \\
\hline Numune 1 & 2,15 & 1,1 & 48,83 & yok & yok & - \\
\hline Numune 2 & 0,54 & 0,3 & 44,44 & 1,24 & 0,85 & 31,45 \\
\hline Numune 3 & 0,62 & 0,45 & 27,42 & yok & yok & - \\
\hline Numune 4 & 1 & 0,52 & 48 & 1,45 & 1,08 & 25,52 \\
\hline Numune 5 & 0,6 & 0,34 & 43,33 & 1,6 & 1,14 & 28,75 \\
\hline Numune 6 & 0,6 & 0,32 & 46,67 & yok & yok & - \\
\hline Numune 7 & yok & yok & - & 2,1 & 1,35 & 35,71 \\
\hline Numune 8 & yok & yok & - & 2,06 & 1,25 & 39,32 \\
\hline Numune 9 & 0,75 & 0,4 & 46,67 & yok & yok & - \\
\hline Numune 10 & 1,42 & 0,75 & 47,18 & yok & yok & - \\
\hline Numune 11 & yok & yok & - & 1,2 & 0,76 & 36,67 \\
\hline Numune 12 & 0,8 & 0,35 & 56,25 & yok & yok & - \\
\hline Numune 13 & yok & yok & - & 1,5 & 0,86 & 42,67 \\
\hline
\end{tabular}

\section{TARTIŞMA VE SONUÇ}

Denim konfeksiyon işletmelerini diğer konfeksiyon işletmelerinden ayıran en önemli özellik; denim konfeksiyon işletmelerinde ürüne yüksek katma değer katan efektlerin bir başka ifade ile ıslak ve kuru işlemlerin uygulanmasıdır. Islak işlemler büyük kazanlar içinde çok sayıda ürüne aynı anda uygulandığından zaman açısından çok sıkıntı yaşatmaz. Fakat kuru işlemler (zımpara, bıyık ve yıpratma gibi) kisa bir süre öncesine kadar tamamen manuel olarak yapılmaktaydı. Bu işlemler manuel yapıldığında çok zaman kaybına yol açmakta, standart bir üretim yapılamamasına neden olmaktaydı. İşletmeler müşterilerine termin verirken direkt ürün üzerindeki kuru işlemleri dikkate almaktaydı. Üstelik denim modası gittikçe daha çok zımpara, daha çok yıpratma ve hatta daha çok yırtık talep etmekteydi. Tüm bunlar da özellikle kuru işlemlerde otomasyonu zorunlu kılmıştır.

$\mathrm{Bu}$ çalışma neticesinde, konfeksiyon işletmelerinin otomasyon sayesinde iş gücü oranının ortalama
\%50 arttığını söyleyebiliriz. Verim iyileşmesinin yanı sıra otomasyon kullanımı ile kalite konusunda da iyileşmeler görülmüştür. Otomasyon kullanımı ile daha standart ürünler çıkmaktadır. Otomasyon kalifiye personel ihtiyacını azaltmış, operatörlerin yetkinlik kazanma süresini kısaltmıştır.

Otomasyonun avantajlarını kısaca kalitede artış, zaman tasarrufu, üretim maliyetinin düşmesi, iş kazalarında azalma dolayısı ile rekabet edilebilirliliğin artması olarak özetleyebiliriz.

Otomasyon sistemlerinin avantajlarının fazla olmasının yanında dezavantajları da var. Bunlar; İlk montaj maliyetinin yüksek olması (Maliyet, uzun zamanda çoğu otomasyon sistemlerinde kendini amorti etmektedir), çalışan sayısında azalma (İşüucü istihdam oranının düşmesi), yatırım maliyetlerinin yükselmesidir.

Bunların yanı sıra, özellikle lazer işlemlerinde, doğal görünümü tercih eden, bu yüzden işlemlerim manuel yapılmasını isteyen denim markaları da mevcuttur. 


\section{TEŞEKKÜR}

Çalışmadaki numunelere ve çalışmama imkan sağladıkları için Baykanlar Tekstil'e (MALATYA) teşekkürü bir borç bilirim.

\section{KAYNAKLAR}

1. Öylek İ., 2014. Hareketli Bant İçeren Bir Otomasyon Prosesinin Veri Matris Kodu Teknikleri Kullanılarak Gerçeklenmesi. Sakarya Üniversitesi, Fen Bilimleri Enstitüsü, Yüksek Lisans Tezi, Sakarya, 92.

2. Erol, E., Paşayev, N., 2014. Küçük ve Orta Ölçekli Konfeksiyon İşletmelerinde Üretim Maliyetlerinin Dikim Bölümü Üretim Şartları Açısından Analizi. Tekstil ve Konfeksiyon Dergisi, 24(1), 134-140.

3. Ciğer, M., 2010. Bilgisayar Kontrollü, İnternet Destekli Sera Otomasyonu. Çukurova Üniversitesi, Fen Bilimleri Enstitüsü, Tarım Makineleri A.B.D, Yüksek Lisans Tezi, Adana, 146.

4. Bilgiç, H., 2017. Denim Konfeksiyonda Otomasyon Uygulamalar1. 2. Uluslararas1 Akdeniz Bilim ve Mühendislik Kongresi (IMSEC 2017) Tam Metin Bildiri, Adana.

5. Yazgan, B.E., Kut, A., Baser, G., Kasap, M., 2002. Web Based Automation Software for Calculating Production Costs in Apparel Industry. Conference: Advances in Information Systems, Second International Conference, ADVIS 2002 October 23-25, Izmir.

6. Chin, K.S., Pun, K.F., Lau, H., Leung, Y.S., 2004. Adoption of Automation Systems and Strategy Choices for Hong Kong Apparel Practitioners. Int J Adv Manuf Technol, 24, 229-240. DOI 10.1007/s00170-003-1592-3.

7. Li, X., Hui, E.C., Lang, W., Zheng, S., Qin, X., 2019. Transition from Factor-driven to Innovation-driven Urbanization in China: A Study of Manufacturing Industry Automation in Dongguan City. China Economic Review. https://doi.org/10.1016/j.chieco.2019.101382.

8. Huang, H.Q., Mok, P.Y., Kwok, Y.L., Au, J.S., 2012. Block Pattern Generation: from Parameterizing Human Bodies to Fit Feature-
Aligned and Flattenable 3D Garments. Computers in Industry, 680-691.

9. Cömert, M., Kadem, D.F., 2015. Dikim Bandında Bir Proses Analizinin Uygulaması. Çukurova Üniversitesi, Mühendislik Mimarlık Fakültesi Dergisi, 30(1), 151-166.

10. Kumaş, Z., Sabır, C.E., Baykal, D.P., 2016. Konfeksiyon İşletmesinin Verimliliği için İş Etüdü Tekniği Kullanımı. Çukurova Üniversitesi, Mühendislik Mimarlık Fakültesi Dergisi, 31(1), 175-190.

11. Ünal, B.Z., Erdoğan, M.Ç., Öndoğan Z., 2005. Konfeksiyon İşletmelerindeki Makinelerin Kârlılık Üzerine Etkileri. Pamukkale Üniversitesi, Mühendislik Fakültesi Mühendislik Bilimleri Dergisi, 11(2), 249-255.

12. http://www.serkonmakina.com (Ekim-2019)

13. Vidyasagar, P.V., 2000. Encyclopedia of textiles-Textile Automation, Vol 3, $1^{\text {st }}$ Edn. Mittal Publications, New Delhi, India, 169.

14. http://www.vavtechnology.com (Eylül-2019)

15. Bilgiç, H., 2015. Örme Konfeksiyonda Kumaş Eni ile Kumaş ve Model Türlerinin Pastal Resmi Verimliliğine Etkileri. Çukurova Üniversitesi, Fen Bilimleri Enstitüsü, Tekstil Mühendisliği A.B.D, Doktora Tezi, Adana, 326. 
